\title{
EDITORIAL
}

\section{Faz sentido ainda propor a separação entre os termos educação formal, não formal e informal?}

Ao longo dos últimos anos a pesquisa na área de educação nos e sobre o que vem sendo convencionado chamar de espaços de educação não formal se ampliaram. O crescimento no interesse pelo tema possui múltiplas influências, as quais referem-se, por exemplo, ao contexto social e político relativo ao papel que a educação popular e a educação ao longo da vida ocupou a partir dos anos de 1960. Especialmente em relação à área de educação em ciências naturais, essa ampliação deve-se, sem dúvida, ao apoio governamental, mas também do setor privado às várias iniciativas de divulgação científica em âmbitos nacionais e internacionais. No Brasil, nos últimos quinze anos, políticas públicas voltadas à inclusão social foram propostas, por meio do fomento a criação de museus e centros de ciência, a realização de feiras de ciência, olimpíadas científicas, semanas nacionais de ciência e tecnologia, etc., com a finalidade de ampliar o acesso e a qualidade das ações de educação e divulgação. Editais de popularização da ciência lançados pelo anteriormente chamado Ministério da Ciência e Tecnologia (hoje Ministério da Ciência, Tecnologia, Inovações e Comunicações), em parceria com outros órgãos, como o Conselho de Desenvolvimento Científico e Tecnológico (CNPq) e a Academia Brasileira de Ciências (ABC), com empresas privadas e fundações (por exemplo, a Fundação Vitae), e pelas Fundações de Amparo à Pesquisa dos estados (FAPs) foram cruciais para a inauguração de museus e centros de ciências em várias regiões do país e para a estruturação e diversificação das atividades já existentes.

Caracterizar os espaços de educação não formal não se constitui em tarefa simples, e, muitas vezes, os termos formal, não formal e informal são utilizados de modo controverso fazendo com que suas definições estejam ainda longe de serem consensuais. Há diferenças de definições nas literaturas anglofônica e lusofônica (CAZELLI, 2000), pois os autores de língua inglesa usam os termos informal science education (educação informal em ciências) e informal science learning (aprendizagem informal em ciências) para todo o tipo de educação que pode acontecer em lugares como museus, centros culturais, exposições, zoológicos, jardins botânicos, no trabalho, em casa, entre outros. Já os de língua portuguesa muitas vezes dividem a educação que ocorre fora da escola em dois subgrupos: educação não formal e educação informal, associando esse último aos ambientes cotidianos familiares, de trabalho, do clube etc. É coerente afirmar que 
esta divisão, muito presente no contexto latino americano, recebeu influência dos movimentos de educação popular intensificados nas décadas de 1960, 1970 e 1980, sendo o termo não formal muitas vezes associado a iniciativas educativas de natureza política e com objetivo de transformação social que marcaram esses períodos. Nos dias atuais, contudo, encontramos referências na literatura que optam por utilizar outras expressões e conceitos que se aproximam da ideia de não formal como "pedagogia social", "educação social" e "aprendizagem por livre-escolha".

A educação não formal tornou-se parte do discurso internacional em políticas educacionais no final dos anos 1960 (SMITH, 1996). Nessa época, esse tipo de educação focava as necessidades de grupos em desvantagens, tendo propósitos claramente definidos e flexibilidade de organização e de métodos. $\mathrm{Na}$ visão de muitos autores que discutem o desenvolvimento desta modalidade educativa, nesse momento o sistema de educação formal, principalmente dos países em desenvolvimento, apresentava uma lenta adaptação às mudanças sócio-econômicas em curso, exigindo que diferentes setores da sociedade se articulassem para enfrentar as novas demandas sociais. Marco desse movimento é o documento da UNESCO, de 1972, Learning to be: the Faure report, que firmou metas quanto à "educação ao longo da vida" (lifelong education) e à "sociedade de aprendizagem" (learning society). Esse documento influenciou uma divisão já visível do sistema educacional em três categorias, problematizadas por Smith (1996) em seu texto amplamente divulgado pela internet, definidas da seguinte maneira:

- educação formal: sistema de educação hierarquicamente estruturado e cronologicamente graduado, da escola primária à universidade, incluindo os estudos acadêmicos e as variedades de programas especializados e de instituições de treinamento técnico e profissional;

- educação não formal: qualquer atividade organizada fora do sistema formal de educação, operando separadamente ou como parte de uma atividade mais ampla, que pretende servir a clientes previamente identificados como aprendizes e que possui objetivos de aprendizagem;

- educação informal: verdadeiro processo realizado ao longo da vida em que cada indivíduo adquire atitudes, valores, procedimentos e conhecimentos da experiência cotidiana e das influências educativas de seu meio - da família, no trabalho, no lazer e nas diversas mídias de massa.

Coombs e Ahmed (1974), no contexto de discussão sobre a crise educacional dos períodos indicados, apontam que essas três modalidades estavam em franca expansão diante de um novo arranjo social que se estabelecia e que não poderiam ser vistas como compartimentos isolados, pois se sobrepõem e geram hibridismos. Smith (1996), destaca, contudo, que tais definições estão fortemente apoiadas na dimensão física do espaço como forma de diferenciá-las, empobrecendo seu potencial de compreensão e análise.

Glória Gohn (1999), especialista brasileira com várias publicações que abordam o tema, nos dá uma outra perspectiva para essa discussão. Para ela, a concepção de educação é mais ampla do que a de aprendizagem e se associa ao conceito de cultura. Desse modo, educação não formal trata de um processo com várias dimensões, relativas à aprendizagem política dos direitos dos indivíduos enquanto cidadãos; capacitação dos indivíduos para o trabalho, por meio de aprendizagem de habilidades; aprendizagem e exercício de práticas que habilitam os indivíduos a se organizarem com objetivos voltados para a solução de problemas coletivos; aprendizagem dos conteúdos da escolarização formal, em formas e espaços diferenciados; e educação desenvolvida na e pela mídia, em especial a eletrônica. Essa autora destaca os vários espaços onde se desenvolvem as atividades de educação não formal como as associações de bairro, os sindicatos, as organizações não-governamentais, os espaços culturais e as próprias escolas, ou seja, nos espaços interativos dessas com a comunidade educativa. Para ela, entretanto, a educação não formal não contempla experiências vivenciadas com e na família, no convívio com amigos, clubes, teatros, leitura de jornais, livros etc., sendo estas categorizadas 
como educação informal, já que possuem caráter espontâneo e permanente. Percebe-se, nessa diferenciação de Gohn, que o foco é o sujeito do processo educativo, pois dependendo dele, de suas intencionalidades e objetivos, uma experiência pode ser considerada não formal ou informal. Diante dessa caracterização algumas questões se colocam: uma família visitando um jardim botânico estaria vivenciando a modalidade não formal ou informal? E o jardim botânico, ao musealizar seu espaço, organizando os organismos vegetais de uma forma específica e divulgando informações por meio de painéis, etiquetas, folders ou mesmo do discurso de um mediador, estaria praticando a modalidade não formal ou informal? E se uma escola visitasse esse mesmo jardim botânico, estaríamos falando de uma educação formal ou não formal? Vemos claramente nestes exemplos as sobreposições destacadas por Coombs e Ahmed (1974), levando-nos inclusive a questionar se é desejável e promissor separar de forma estanque essas experiências educacionais e, no limite, questionar se realmente essas definições são necessárias e ainda fazem sentido no contexto educacional do século XXI.

Para tornar o tema ainda mais complexo, há na literatura concepções que se voltam para o processo de aprendizagem. Falk e Dierking (2002) cunharam a expressão free-choice learning (aprendizagem por livre escolha) como forma de enfrentar a confusão entre os termos formal, não formal e informal. Para eles, a "aprendizagem por livre escolha" é todo tipo de aprendizagem que pode ocorrer fora da escola, especialmente em museus, centros de ciências, organizações comunitárias e nas mídias impressa e eletrônica (incluindo a Internet). Na "aprendizagem por livre escolha", o interesse e a intenção do aprendizado tem origem no indivíduo, logo não é imposta por elementos externos, como ocorre na escola. Mais uma vez identificamos na literatura que o sujeito aparece como centro do processo educacional e elemento definidor que impõe a fronteira de separação entre as três modalidades educacionais.

Uma proposta promissora para o enfrentamento da pluralidade de visões sobre o termo não formal é a de Rogers (2004), que afirma que a educação não formal e a informal, em conjunto com a educação formal, devem ser vistas como um continuum em vez de categorias estanques. Se considerarmos os critérios que diferentes pesquisadores e educadores utilizam para definir esses contextos (MARANDINO et al., 2004) e tendo em mente a ideia de continum proposta por Rogers (2004), poderíamos imaginar que alguns critérios demarcam as experiências formais, não formais e informais, como: seus propósitos, a forma de organização do conhecimento, o tempo de desenvolvimento das ações, a estrutura com que é organizada, as formas e os agentes/sujeitos que controlam as práticas e a própria experiência e a intencionalidade que a fundamenta. A partir desses critérios, e considerando o continumm entre essas modalidades educacionais, podemos analisar as instituições e as variadas atividades educacionais desenvolvidas em diferentes espaços, organizações e grupos, de forma integrada ou separadamente. Podemos ainda observá-lo pelos olhos da instituição ou do sujeito da aprendizagem. Dessa forma, um museu, por exemplo, poderia ser nomeado como um espaço de educação não formal quando o pensamos como uma instituição que possui um projeto estruturado e com um determinado conteúdo programático e, em especial, com intencionalidades educativas determinadas. Contudo, sob o olhar do público, poderíamos considerá-lo, por exemplo, como educação formal, quando alunos o visitam com uma atividade totalmente estruturada por sua escola, buscando um aprofundamento em um determinado conteúdo específico. E podemos, ainda sob o olhar do público, imaginá-lo como educação informal, ao pensarmos em um visitante que procura um museu para uma experiência de fruição e entretenimento em um final-de-semana com seus amigos ou familiares.

É possível assim afirmar que a expressão educação não formal é polissêmica, fruto também do fato de ser constituída pela própria negação da ideia: aquilo que não é formal! Além 
disso, uma rápida busca na internet sobre o termo revela que muitas vezes a diferenciação se dá em bases de atribuição de valores sobre práticas mais conservadoras e transmissivas (associadas, nesses casos, ao termo formal) e aquelas mais participativas e auto-gestionadas (chamadas de não formais). Aqui, nos parece relevante entender que a proposição do termo não formal, na sua origem, como comentamos anteriormente, esteve vinculada a crise educacional e ao questionamento do papel reprodutor da escola em meados do século XX, aproximando-o da educação popular. Assim, não é à toa que vemos muitas vezes a associação do não formal a práticas e estratégias políticas, reflexivas e críticas, consideradas nesse caso "melhores" ou "mais adequadas" ao contexto atual do que as ditas "formais". Vale, contudo, questionar essa visão, já que ela não considera a pluralidade e a eficácia de práticas educativas transformadoras e reflexivas que as escolas (formal) também podem propiciar aos alunos e alunas. E ainda não considera os limites e desafios da própria educação não formal.

Importante mencionar que educação popular é um campo também repleto de debates e as articulações e as tensões entre a educação escolar e a educação popular é um tema explorado na literatura sobre esse tema. Carlos Brandão, um autor referência na discussão da educação popular, aborda em algumas de suas obras a articulação entre os movimentos populares e a luta pelos direitos populares à educação escolar (BRANDÃO, 2000, 2007). Nessa linha, Streck (2013) afirma que a educação popular é um movimento pedagógico de resistência à dominação, seja ela de classe, de raça, de gênero ou outras e aponta que a educação popular e a educação básica podem estar, do ponto de vista ideológico e pedagógico, no mesmo campo ou em campos opostos. Tais considerações fornecem elementos importantes para uma reflexão sobre os valores e significados que têm sido dados a expressão não formal, nos provocando a sermos cuidadosos e críticos ao assumir determinadas vertentes desse amplo e complexo debate.

Faz sentido hoje ainda propor a separação entre formal, não formal e informal e dar continuidade a busca por uma definição para o termo não formal? A possível resposta a essa pergunta possui uma dimensão epistemológica e outra política. Como vimos, há aspectos relevantes nas diversas tentativas de definição do termo, que envolvem a necessidade de aprofundar em diversos tópicos da área educacional relativos à história, política, filosofia e sociologia da educação, mas também a didática, currículo e as articulações desses com os campos específicos de conhecimento, como por exemplo as ciências naturais. Nos parece que o movimento de aprofundamento e articulação teórica dentro da área da educação, promovido pelo exercício de definição do termo não formal, tem promovido reflexões ricas e interessantes sobre as práticas educativas realizadas pela escola e pelas diferentes instituições e organizações culturais, e sobre as relações entre essas várias instâncias. Esse movimento tem contribuído para uma melhor compreensão e legitimação da própria área educacional, o que pode ser um bom argumento para que continuemos buscando uma definição. $O$ fato de que as experiências reais nem sempre se enquadrem totalmente nas definições que atualmente estão disponíveis não pode ser entendido como justificativa para que não continuemos a buscar um melhor entendimento do significado da educação não formal.

Por outro lado, como nos aponta Bourdieu (1996), a constituição de novos campos de conhecimento implica igualmente na constituição de novos campos de força, as quais se dão frente a disputas de poder, com a possibilidade de constituição de novos agentes que, por sua vez, podem ocupar posições diferenciadas dentro destes campos, mantendo ou modificando sua estrutura. Se considerarmos os investimentos ocorridos nos últimos anos tanto para a educação formal e como para a não formal e as disputas pelas fontes de financiamento feitas pelos agentes envolvidos com essas modalidades, podemos compreender que a construção da ideia de educação não formal não é uma questão somente epistemológica, mas envolve também 
dimensões políticas e econômicas. Diante do momento histórico atual de restrição financeira e de disputas entre projetos sociais e educacionais críticos e conservadores, é sem dúvida necessária uma profunda reflexão sobre os sentidos da educação não formal.

Martha Marandino

Universidade de São Paulo (USP), Faculdade de Educação, Departamento de Metodologia do Ensino e Educação Comparada, São Paulo, SP, Brasil. E-mail: <marmaran@usp.br>.

\section{Referências}

BOURDIEU, P. Razões práticas: sobre a teoria da ação. Campinas: Papirus, 1996.

BRANDÃO, C. R. Educação popular. 2. ed. São Paulo: Brasiliense, 2007.

Educação popular na escola cidadã. Petrópolis: Vozes, 2000.

CAZELLI, S. Divulgação científca em espaços não formais. In: CONGRESSO DA

SOCIEDADE DE ZOOLÓGICOS DO BRASIL, 24, 2000, Belo Horizonte. Anais... Belo Horizonte, MG: Sociedade Brasileira de Zoologia, 2000.

COOMBS, P. H. The world crisis in education. New York: Oxford University Press, 1985.

COOMBS, P. H.; AHMED, M. Attacking rural poverty: how nonformal education can help. Baltimore: The John Hopkins University Press, 1974. Disponível em: < http:// documents.worldbank.org/curated/en/656871468326130937/pdf/multi-page.pdf>. Acesso em: 24 out. 2017.

FALK, J. H.; DIERKING, L. D. Lessons without limit: how free-choice learning is transforming education. Walnut Creek, CA: AltaMira Press, 2002.

GOHN, M. G. Educação não-formal e cultura política: impactos sobre o associativismo do terceiro setor. São Paulo: Cortez, 1999.

MARANDINO, M. et al. A educação não formal e a divulgação científica: o que pensa quem faz? In: ENCONTRO NACIONAL DE PESQUISA EM ENSINO DE CIÊNCIAS, ENPEC, 4., 2004, Bauru. Atas... Disponível em: <http://paje.fe.usp.br/estrutura/geenf/ textos/oquepensa_trabcongresso5.pdf>. Acesso em: 24 out. 2017.

ROGERS, A. Looking again at non-formal and informal education: towards a new paradigm. In: . Non-formal education: flexible schooling or participatory education? Hong Kong: The University of Hong Kong, 2004. Disponível em: < http://www.infed.org/biblio/ non_formal_paradigm.htm>. Acesso em: 24 out. 2017.

SMITH, M. K. What is non-formal education? 1996. Disponível em: <http://www.infed. org/biblio/b-nonfor.htm>. Acesso em: 24 out. 2017. 
STRECK, D. R. A pesquisa em educação popular e a educação básica. Práxis Educativa, Ponta Grossa, v. 8, n. 1, p. 111-132, 2013. Disponível em: < https://doi.org/10.5212/

PraxEduc.v.8i1.0005>. Acesso em: 24 out. 2017.

Endereço para contato: Avenida da Universidade, 308, Cidade Universitária, Butantan, CEP 055080-40, São Paulo, SP, Brasil. 